\title{
Natural gas intracyclic attachment for energy generating unit based on gas turbine plant
}

\author{
Dmitriy Kalashnikov ${ }^{1,2 *}$, Yuriy Borisov ${ }^{1,2}$ and Elizaveta Kalashnikova ${ }^{3}$ \\ ${ }^{1}$ Joint Institute for High Temperatures, Russian Academy of Sciences, Ijorskaia str. 13/2, Moscow, Russia \\ ${ }^{2}$ Bauman Moscow State Technical University, $2^{\text {nd }}$-Baumanskaia str. 5, Moscow, Russia \\ ${ }^{3}$ PJSC “ALMAZ R\&P Corp.” LEMZ DIVISION, Dmitrovskoie route 110, Moscow, Russia
}

\begin{abstract}
In this article, problems of effectiveness increasing in complex power supply are considered. Disadvantages of centralized power engineering and advantages of power engineering capabilities organization in immediate consumer proximity are presented. Consumer needs satisfaction in electricity, heat supply and cold supply are offered to be realized by conversion of district and quarter boiler houses to trigeneration stations, which are based on gas turbine plants units. In this research, solutions of problem related to lack of fuel gas pressure for gas turbine engine power, which is included in gas turbine plant of trigeneration stations, are suggested. As a result, after considering possible variants of fuel gas pressure increasing, it was decided that there is a perspective of using fuel gas intracyclic compression attachment. Its operating principle involves organization of main steam extraction in heat cycle for booster compressor drive, which compresses fuel gas before its transfer to combustor of gas turbine plant. Results of gas compressor and drive steam turbine design are presented. These parts are included in fuel gas intracyclic compression attachment in specific unit of gas turbine plant. Also, general recommendations about new compressor and turbine stages design for any other units of gas turbine plant are pointed. Further, in the article, two variants of thermal circuit, based on gas turbine plant, are suggested. The first one is a circuit with hot water boiler, where exhaust gas recuperation after turbine is carried out for producing steam, related to fuel gas intracyclic compression attachment demands, and heat system water heating for consumer heat supply system. The second variant involves development of typical gas turbine plant unit in power station with exhaust boiler. There fuel gas intracyclic compression attachment is activated by steam work after exhaust boiler. Then, variants of diagram are compared between each other. Also advantages and disadvantages each of them are considered.
\end{abstract}

\section{Introduction}

Reliable and efficient power supply is one of the most important targets of a government. The degree of power generation centralization causes extremely large impact on efficiency of power supply. For example, approximately $94 \%$ of all electric power of the country is generated in large-scale power plants (installed capacity exceeding $25 \mathrm{MW}$ ) [1]. Just a little more than $6 \%$ of power is generated by means of the so-called small or distributed power. Meanwhile, most of this capacity is industrial power, i.e. it is power supply of large-scale enterprises by means of small power plants owned by these enterprises. Such situation is explained by low cost of power generation on large-scale power plants due to high efficiency of fuel transformation and lowering of production costs.

But, apart from power, consumers need heat supply and, due to rising comfort requirements, cold supply. Due to the above said, the negative features of large- scale centralized energy are becoming clear. Such features include large losses during energy transportation as well as impossibility of connection of a significant number of both civil and military hard-toreach facilities to it. While the electric energy transportation losses are about $13 \%$ as of 2018 , the heat energy losses reach $40 \%$ [2]. As a result of inefficiency or impossibility of heat supply of consumers by means of large-scale HPP's, about $70 \%$ of heat energy is generated by district, block and household heating stations. But analysis of efficiency of such heating stations shows the same extremely high level of heat energy losses as that in case of large-scale HPP's. It is caused by obsolete or worn equipment of heating stations as well as by bad state of heat networks.

Speaking of cold generation, each consumer shall supply cold by own efforts since centralized cold supply does not exist. This is caused by the fact that cold transportation is by an order more expensive than heat transportation (temperature difference in a non-return 
and a return pipe is $6 \mathrm{~K}$ whereas in heat networks it may reach $100 \mathrm{~K}$, hence, with specific flow rate of $25 \mathrm{~kW}$, the water carries $25 \mathrm{~kW}$ in a cold supply network and 400 $\mathrm{kW}$ in a heat network). That is why cold supply is not specified in most of premises projects. Owners of premises install air conditioning systems at their discretion. That's why centralized cold supply systems are extremely rare.

Based on the aforesaid, the necessity of transition to new power supply technologies is becoming obvious. One of the most promising directions of power supply technology enhancement is replacement of district and block heating stations with trigeneration units. The trigeneration units combine generation of electricity, heat and cold in a united energy unit. Potential of the trigeneration units is based on mutual energy cascading sufficiently increasing fuel efficiency [3]. In this case the optimal degree of energy centralization moves to the area of block power generation units based on lowcapacity gas-turbine units (GTU).

The advantages of such units are high degree of automation, capability to operate without servicing personnel for a long time as well as remote control from a united remote control centre. Gas turbine plant units are also highly flexible, which allows to provide energy to consumers in accordance with current values of load graphs [4].

One of the most significant factors hindering application of GTU-based trigeneration units instead of conventional block heating stations is insufficient pressure in a gas line for supply of fuel for such units. In accordance with existing sanitary and environmental standards, medium pressure $(0.005$ to $0.3 \mathrm{MPa})$ gas is supplied to residential districts; in rare cases, a seconddegree high-pressure line $(0.3$ to $0.6 \mathrm{MPa})$ is routed. Such pressure is not sufficient for normal combustion processes in a GTU burner. Due to this fact, booster compressor stations are required [5] to increase gas pressure in a gas line up to values required in accordance with the operation mode of a GTU burner.

Such compressor stations are not convenient in residential districts: their installation is expensive; they require additional buildings and their drives require significant electric capacity. This electric capacity is used extremely inefficiently as the gas flow should be restricted down to lower values of pressure after compressing in accordance with the unit load requirements at a specific moment. The velocity and range of fuel flow and pressure changing are determined by the requirements of operation mode control of a GTU burner. Due to the above-mentioned factors, the economic advantage of application of the described GTUs reduces.
Alternative method of increasing of gas pressure in a burner of a GTU burner is installation of additional equipment which not only boosts gas but also controls its flow directly during the unit cycle. We will call such additional equipment a fuel gas intracyclic compression attachment for GTU-based energy generation unit.

\section{Development of intracyclic compression complex for a power generating unit based on a gas turbine unit}

Generally, a natural gas intracyclic compression attachment for an energy generation unit is a system consisting of a high-speed small gas compressor, a steam turbine and a synchronous motor generator mounted on one shaft. The gas compressor driven by the steam turbine compresses the fuel gas down to the value of pressure required at a specific moment in a GTU burner. Gas pressure and current flow are controlled by means of the synchronous motor generator. Depending on the requirements of a GTU specific operation mode, the synchronous motor generator may increase power draw of the system shaft or act as an additional load operating in a generator mode.

For analysis of efficiency of the fuel intracyclic compression technology, 2.5 MW GTU-2.5P developed by ODK-Aviadvigatel JSC on the basis of D-30 aircraft engine was selected. In nominal operation conditions, the GTU-2.5P compressor delivery pressure of air is about 0.6 MPa. For supply of fuel gas into a burner, its pressure shall exceed the compressor delivery pressure of air by $0.1-0.2 \mathrm{MPa}$. Hence, in nominal operating conditions of GTU-2.5P, the intacyclic gas compression unit shall provide output pressure of fuel gas (methane) of $0.8 \mathrm{MPa}$ at flow rate of $0.246 \mathrm{~kg} / \mathrm{s}(886 \mathrm{~kg} / \mathrm{h})$. Since the minimal pressure of fuel gas in a gas distribution network may be equal to $0.4 \mathrm{MPa}$, the generator compressor pressure ratio should be equal to 2 . The above-mentioned values may be taken as input data for development of specific compressor and turbine equipment.

As the most appropriate blower, a centrifugal compressor was developed which contains an impeller with a cover plate and backward bent vanes (fig. 1) and a channel diffuser [6]. Apart from reducing of losses by reducing thrust clearance leakage, the cover plate allows to form a surface for installation of a gas-lubricated thrust bearing. The backward bent vanes allow to increase efficiency factor. 


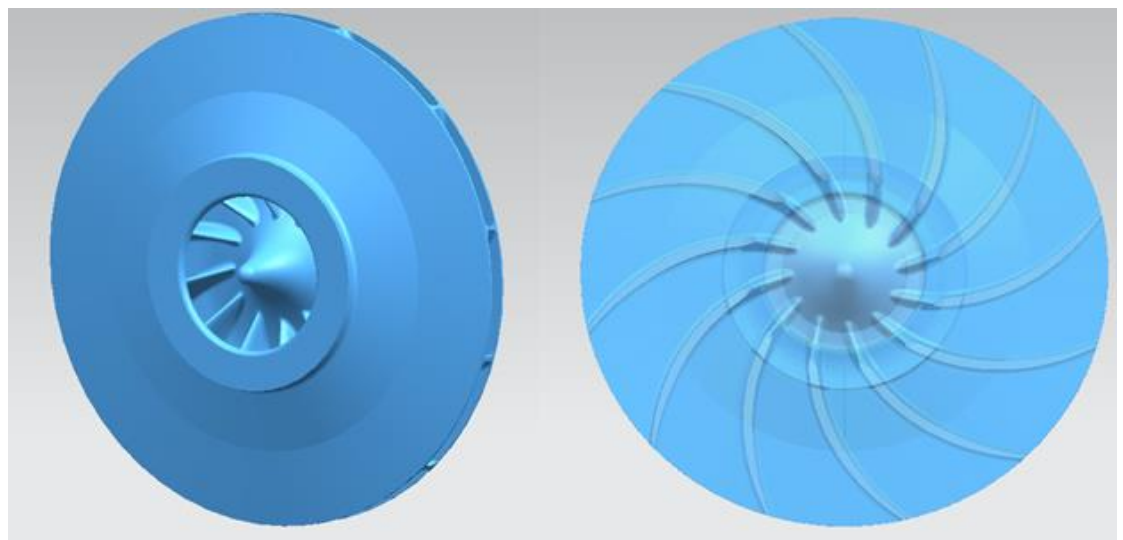

Fig. 1. Model of the impeller of the developed compressor

During design, special attention should be paid to a way of fixation of the impeller on the unit shaft. Conventional method of installation of a compressor impeller on a shaft is characterized by availability of a central opening which is a stress raiser. Disadvantages of this mounting method include limitations of the size of an impeller and its hub-tip ratio. That's why a decision was made to reject the conventional method of compressor impeller installation on a shaft. Press fit is proposed as a method of torque transmission; thus, the stress raiser is moved to the least loaded area (fig. 2). Such solution allows to transmit torque of up to $10 \mathrm{Nm}$, which corresponds the power of $90 \mathrm{~kW}$ at rated speed of $87,000 \mathrm{rpm}$. The obtained specifications of the developed compressor are shown in figure 3. The calculation point is shown in violet.

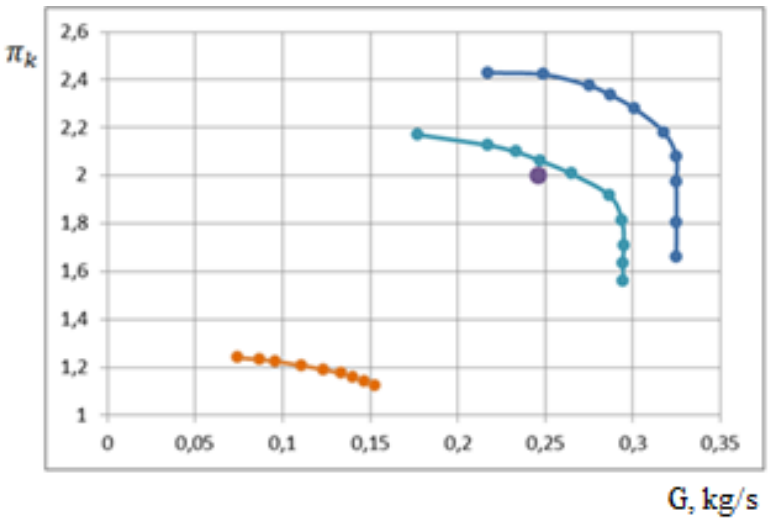

Fig. 3. Design characteristics of the developed compressor

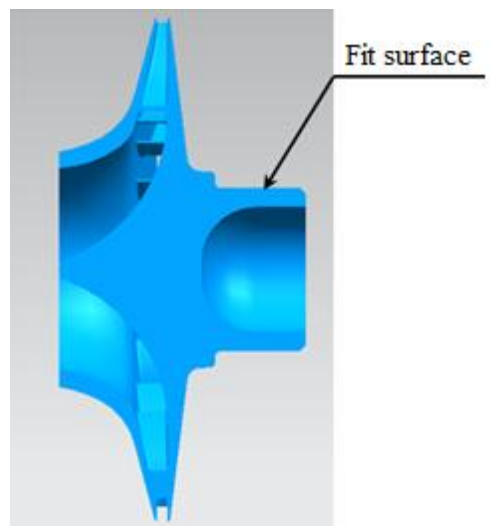

Fig. 2. Axial section of the impeller of the developed compressor

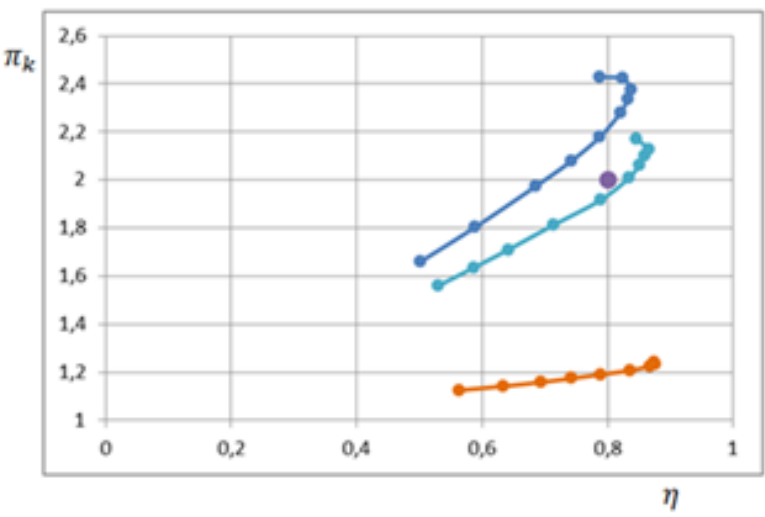

( $\longrightarrow$ - n=96000 rpm; $\longrightarrow$ - n=87000 rpm; $\longrightarrow$ - n=43500 rpm)

The analysis of specifications of the designed booster compressor allows to make a conclusion that it complies with the requirement of supply of fuel gas to GTU-2.5P at required pressure and flow rate within a wide adjustment range.

A turbine is required to be designed as a drive for the above-mentioned compressor. The main parameter to be considered during selection of a turbine drive for the developed compressor regulator is power. The power required for operation of the compressor in different modes may be defined using the following formula:
$N=G \cdot c_{p} \cdot\left(T_{2}^{*}-T_{1}^{*}\right)$

where $G$ is gas mass flux, $\mathrm{kg} / \mathrm{s} ; c_{p}$ is gas specific heat at constant pressure, $\mathrm{J} / \mathrm{kg} \times \mathrm{K} ; \mathrm{T}_{1}{ }^{*}, \mathrm{~T}_{2}{ }^{*}$ are compressor inlet and outlet temperatures respectively, $\mathrm{K}$.

The compressor power consumption dependence on gas flux at different values of rated speed is shown in fig.4. 


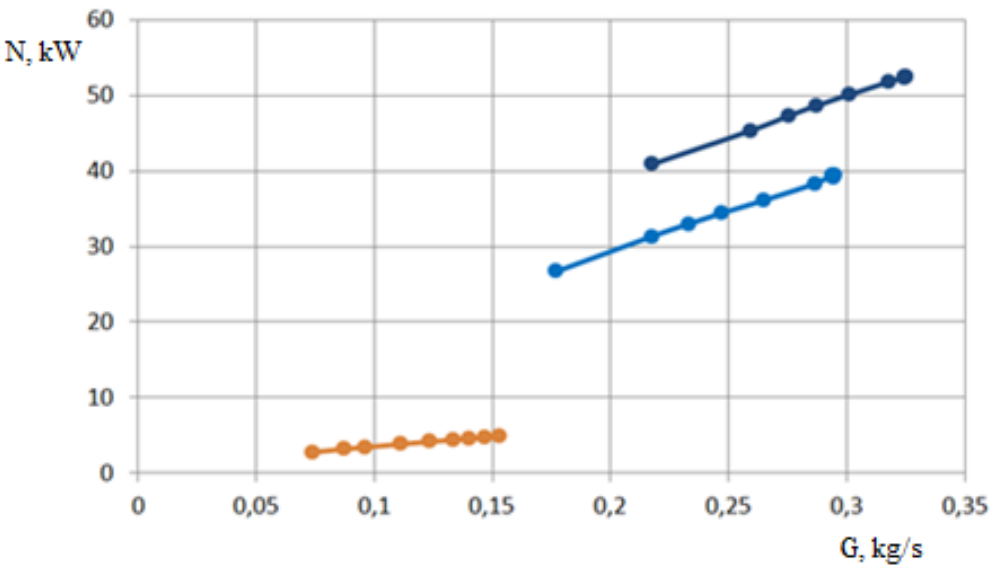

Fig. 4. Dependence of the power consumed by the compressor on the gas flow rate $(\longrightarrow-\mathrm{n}=96000 \mathrm{rpm} ; \longrightarrow-\mathrm{n}=87000 \mathrm{rpm} ;-\mathrm{n}=43500 \mathrm{rpm})$

Since the designed compressor regulator shall provide minimum transition time between operation modes of GTU-2.5P, the drive power shall be at least 1.7 times higher than the compressor power in nominal mode. Hence, the output power of the turbine at compressor shaft rated speed of $87,000 \mathrm{rpm}$ should be of at least $60 \mathrm{~kW}$.
For this purpose, a steam turbine is proposed to be used [7]. It is recommended to use a closed radial-flow impeller (fig. 5), which allows to reduce rotor-tip leakages of steam. The method of fixation of the turbine impeller on the shaft is similar to that used for fixation of the compressor impeller.

The turbine specifications in nominal mode obtained by calculation are shown in table 1 .

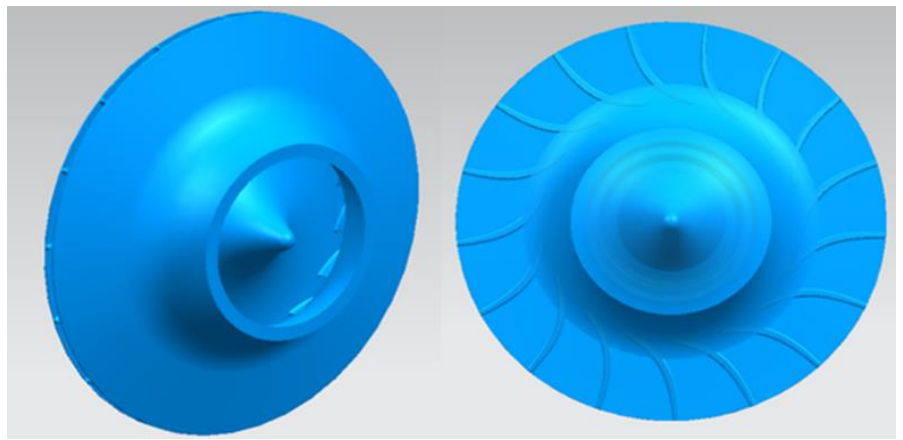

Fig. 5. The model of the impeller developed by the turbine

Table 1. Parameters of the steam turbine of the intracycle gas compression complex

\section{Parameter}

Working fluid

Turbine expansion ratio

Adiabatic Turbine

Efficiency

Value

Dry

steam

Actual gas flow through

the turbine

Actual turbine speed

The power consumed

by the turbine
1,91

$\mathrm{kg} / \mathrm{s}$

87000

rpm

60,9

$\mathrm{kW}$

\section{Parameter}

The total gas pressure

Value

at the inlet to the turbine

The total gas pressure

As the power generated by the steam turbine of the intracyclic compressor system is higher than the power consumed by the compressor in most cases, it is necessary to provide transformation of excess power into electric energy transferred to consumers.

For this purpose, it is necessary to us a motor generator with its rated power close to rated power consumed by the compressor of the intracyclic fuel compression system, and its dimensions don't exceed the diameters of the designed compressor and turbine.

\section{Design of arrangements of GTU. based power generating unit with a}




\section{intracyclic fuel gas compressor attachment}

One of possible arrangements of the GTU-2.5P-based energy generation unit with a fuel gas intracyclic compression attachment is formation of an energy

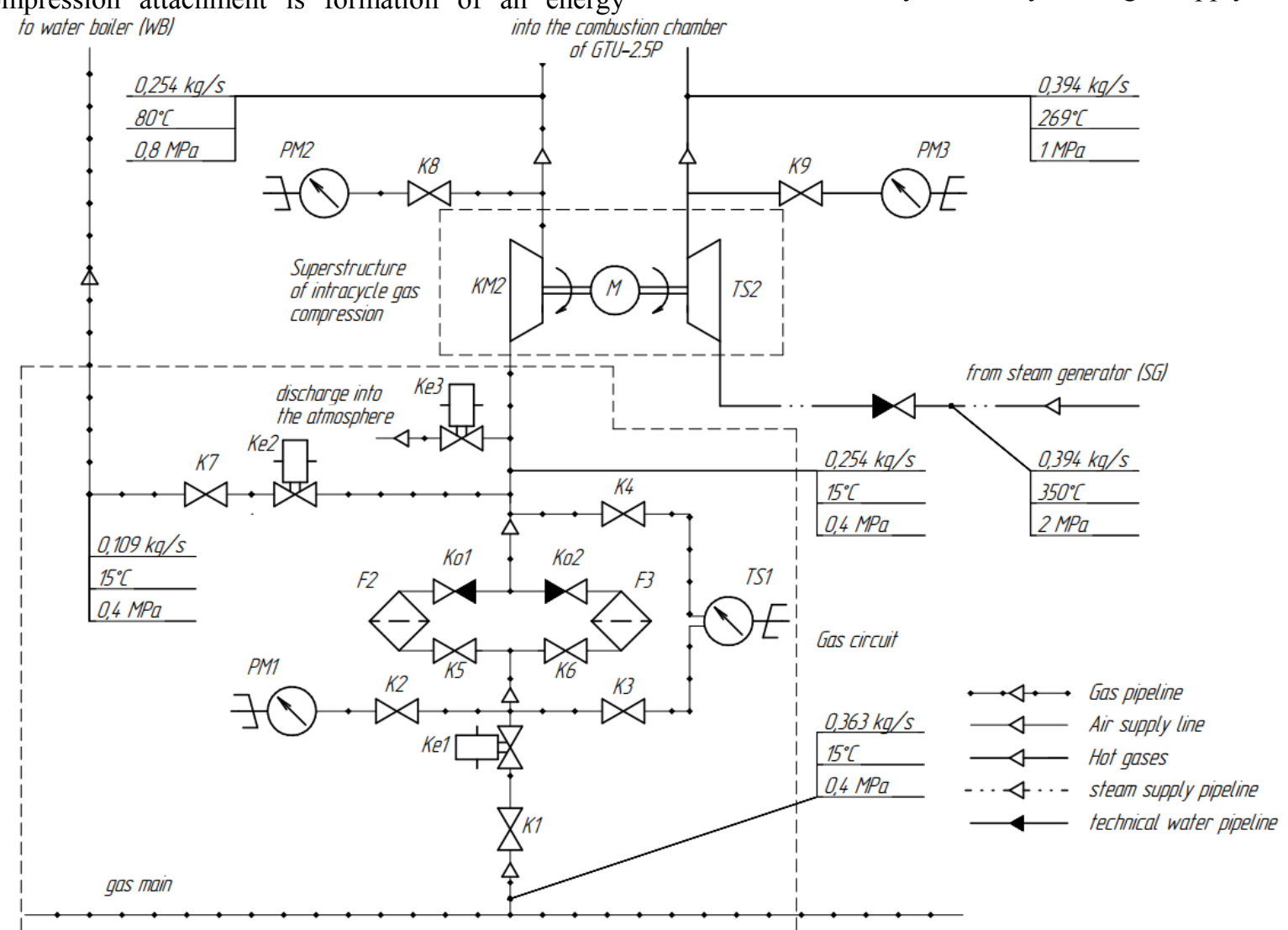

Fig. 6. The gas supply circuit and the intra-cycle compression complex of a variant of the scheme with a gas-fired hot water boiler

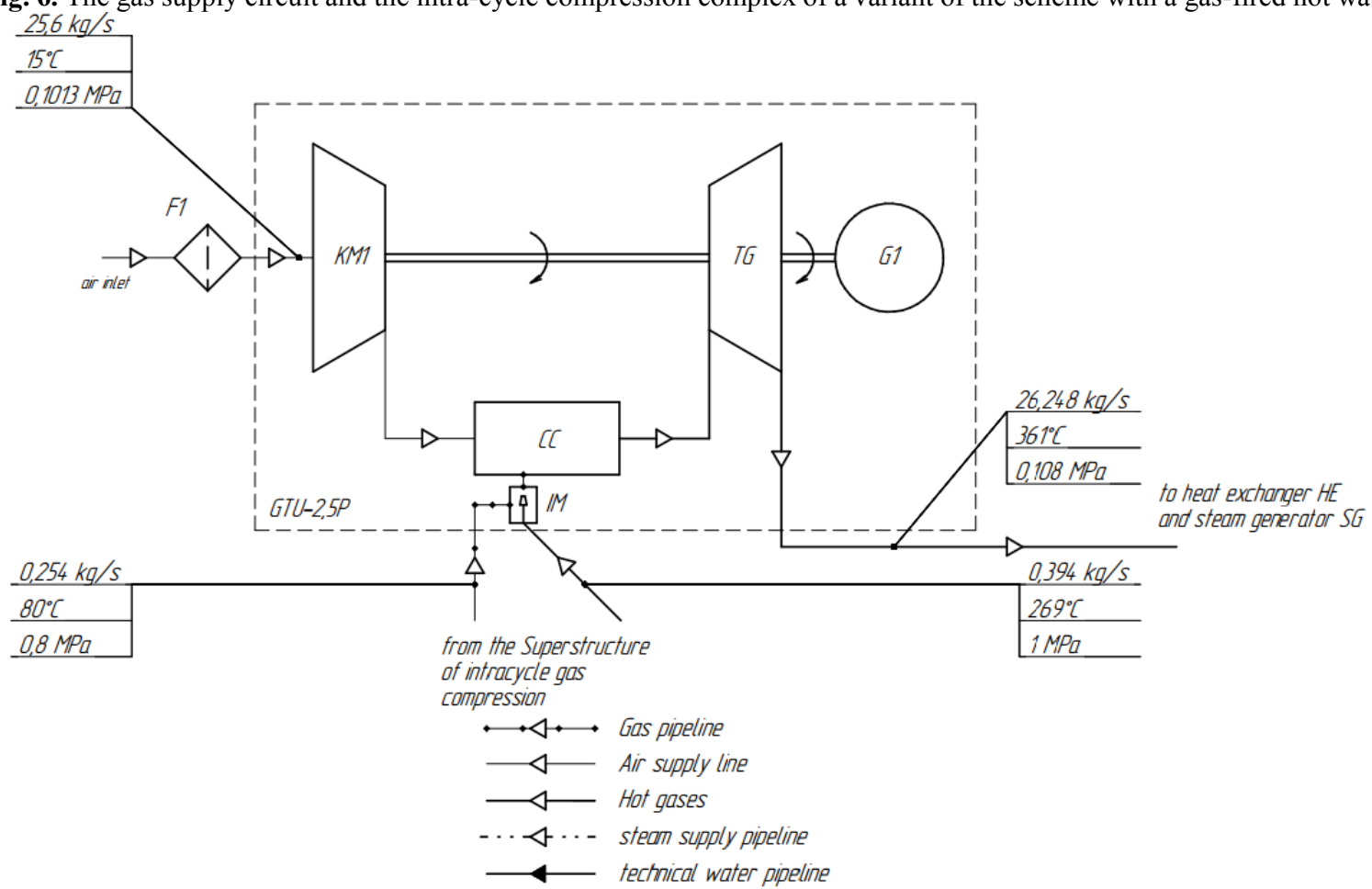

Fig. 7. Provision of GTU-2.5P version of the scheme with a gas-fired hot water boiler 


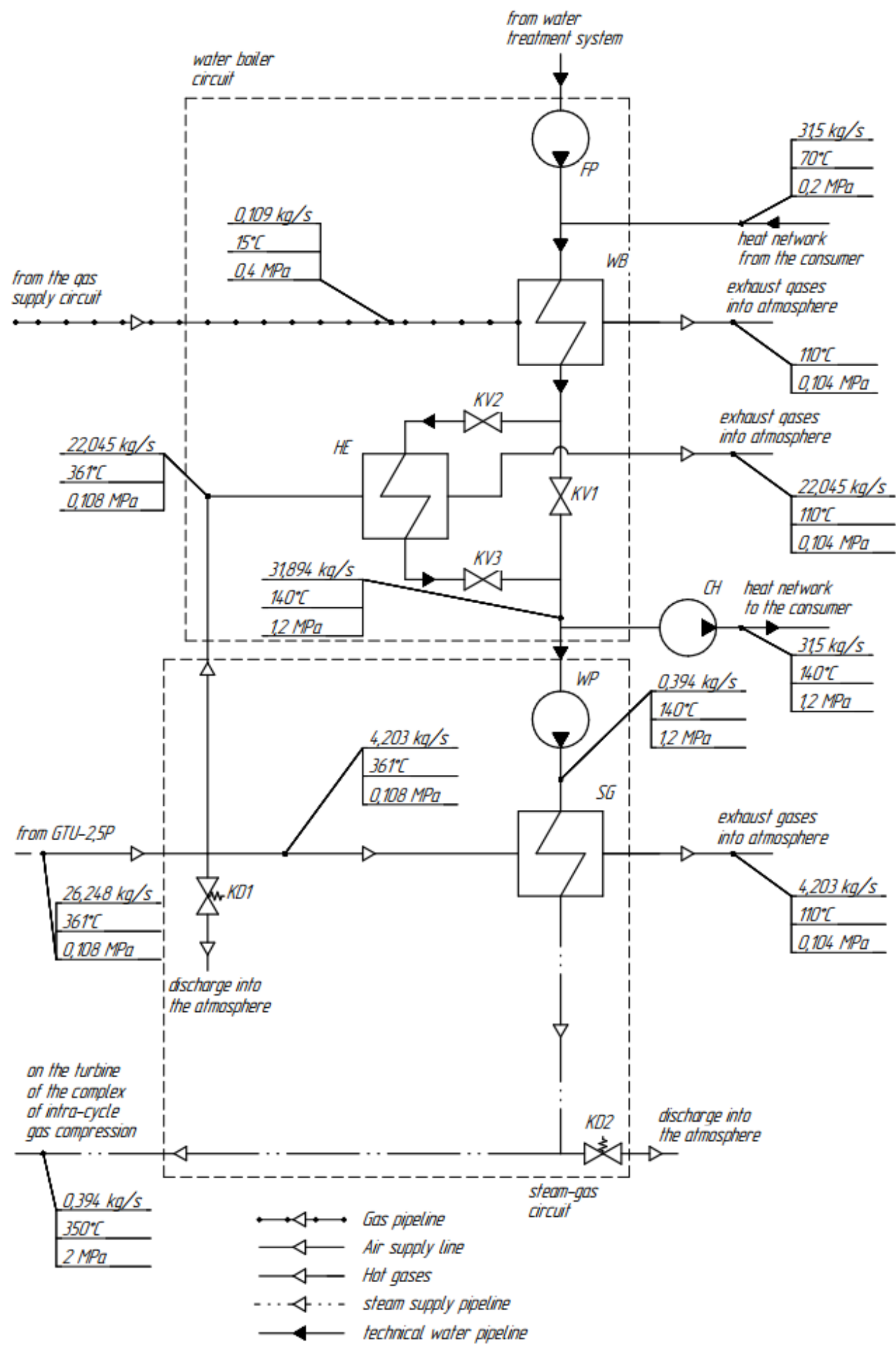

Fig. 8. Hot-water and steam-gas contours of a variant of the scheme with a gas-fired hot water boiler 
The primary energy source is supplied by the 0.4 $\mathrm{MPa}$ gas line in this arrangement (fig. 6). Any other lesser pressure value complying with the WB hot water boiler supply requirements is possible. One or more supply routes from the gas line capable to provide gas mass flux of at least $0.36 \mathrm{~kg} / \mathrm{s}$ are arranged. After filtering in the F2 and F3 filters, the gas flow is divided into two parts. One part is sent to the WB hot water boiler, the other one is sent to the intracyclic gas compression unit. Increase of gas pressure is performed by means of the KM2 compressor driven by the TS2 steam turbine and their rotation is adjusted by means of the $\mathrm{M}$ motor generator.

After increasing After increasing of pressure in the $\mathrm{KM} 2$ gas compressor, the gas pressure reaches $0.8 \mathrm{MPa}$, which is sufficient for operation of GTU-2.5P (fig. 7). Then it is mixed with steam operated in the TS2 steam turbine. Mixing is performed in the SI injector mixer which supplies the steam and gas mixture to the burner of GTU-2.5P. Addition of a small amount of water steam in the burner of GTU-2.5P allows to reduce adverse influence of nitrogen oxides generation inside it. These adverse compounds on inner walls of the burner may cause generation of points with very high temperature, which causes adverse impacts on service life of the burner. The air filtered by means of the F1 filter is also supplied into the burner by means of the KM1 compressor installed in GTU-2.5P. After mixing the steam and gas mixture and air, fuel is combusted. Then hot gas rotates the TG gas turbine. On one shaft with the TG gas turbine, there is the G1 power generator which generates electricity. The efficiency factor of the gas-turbine engine is about $25 \%$. It means that fuel energy is used extremely inefficiently in case the gas which passed the TG gas turbine is discharged directly into atmosphere. After passing the gas turbine, the gas has high temperature, so its heat is necessary to be transferred to secondary energy sources to increase efficiency of fuel use. This arrangement proposes to use heat for additional heating up of heating water after passing the WB hot water boiler and for generation of steam in the SG steam generator for the TS2 steam turbine drive installed in the fuel gas intracyclic compression unit (fig. 8). Heating up of heating water in the HE heat exchanger allows to significantly reduce fuel gas flux in the WB hot water boiler. For example, for production of $9.318 \mathrm{MW}$ of heat nominal for such unit, the hot water boiler requires $0.236 \mathrm{~kg} / \mathrm{s}$ of fuel gas. If the WB hot water boiler operates in conjunction with the HE heat exchanger, it will require just $0.109 \mathrm{~kg} / \mathrm{s}$ of fuel gas, which is more than twice as efficient. As a result, for supply of such arrangement, $0.363 \mathrm{~kg} / \mathrm{s}$ of fuel gas is required. The energy generation unit also generates up to $2.5 \mathrm{MW}$ of electric energy.

Another possible option is formation of an energy generating unit like a typical GTU of a power plant with a waste heat boiler [10]. An example of such arrangement is shown in figures 9 and 10 .

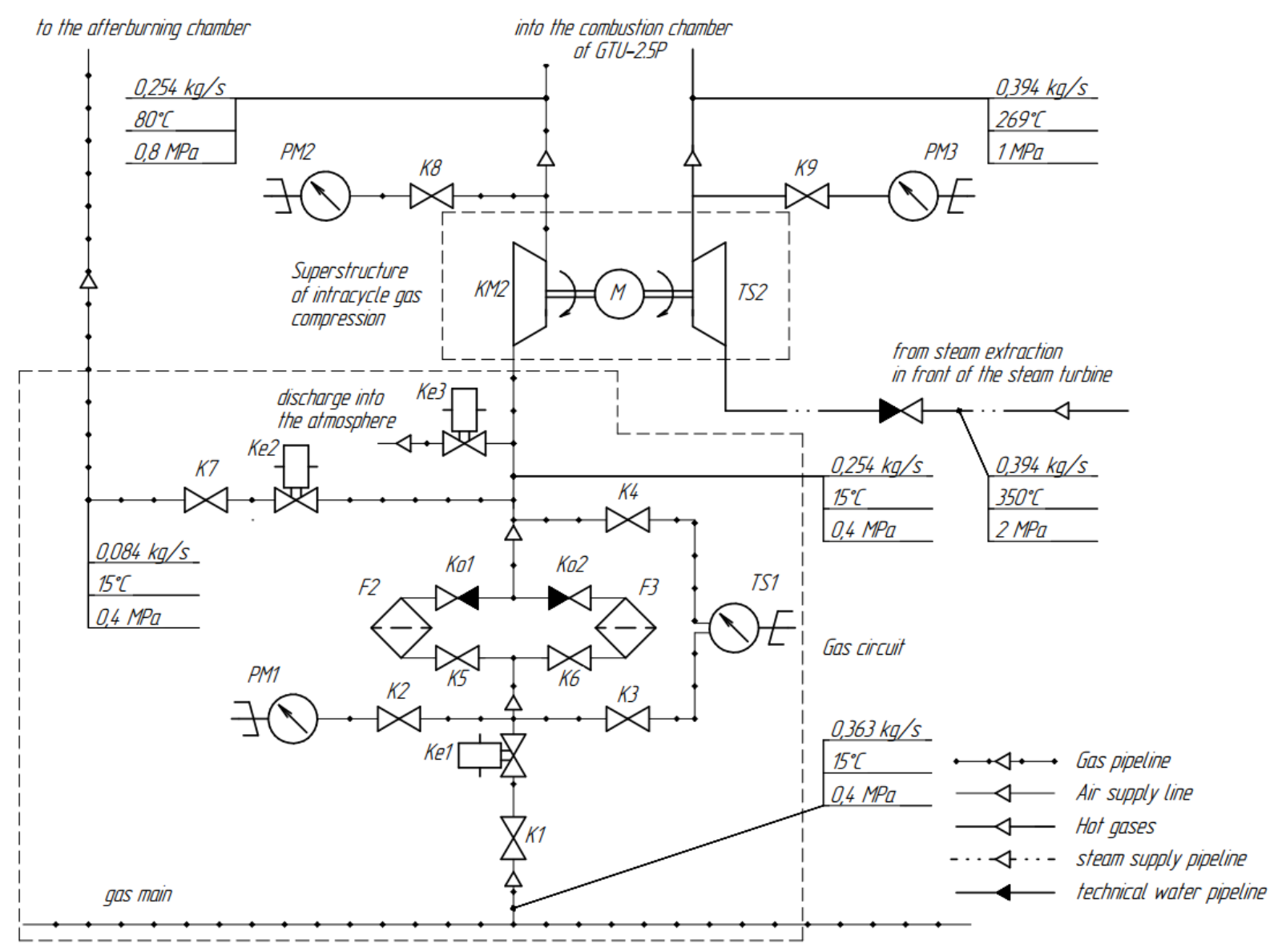


Fig. 9. Gas supply circuit and intra-cycle compression complex of a variant with a waste-heat boiler

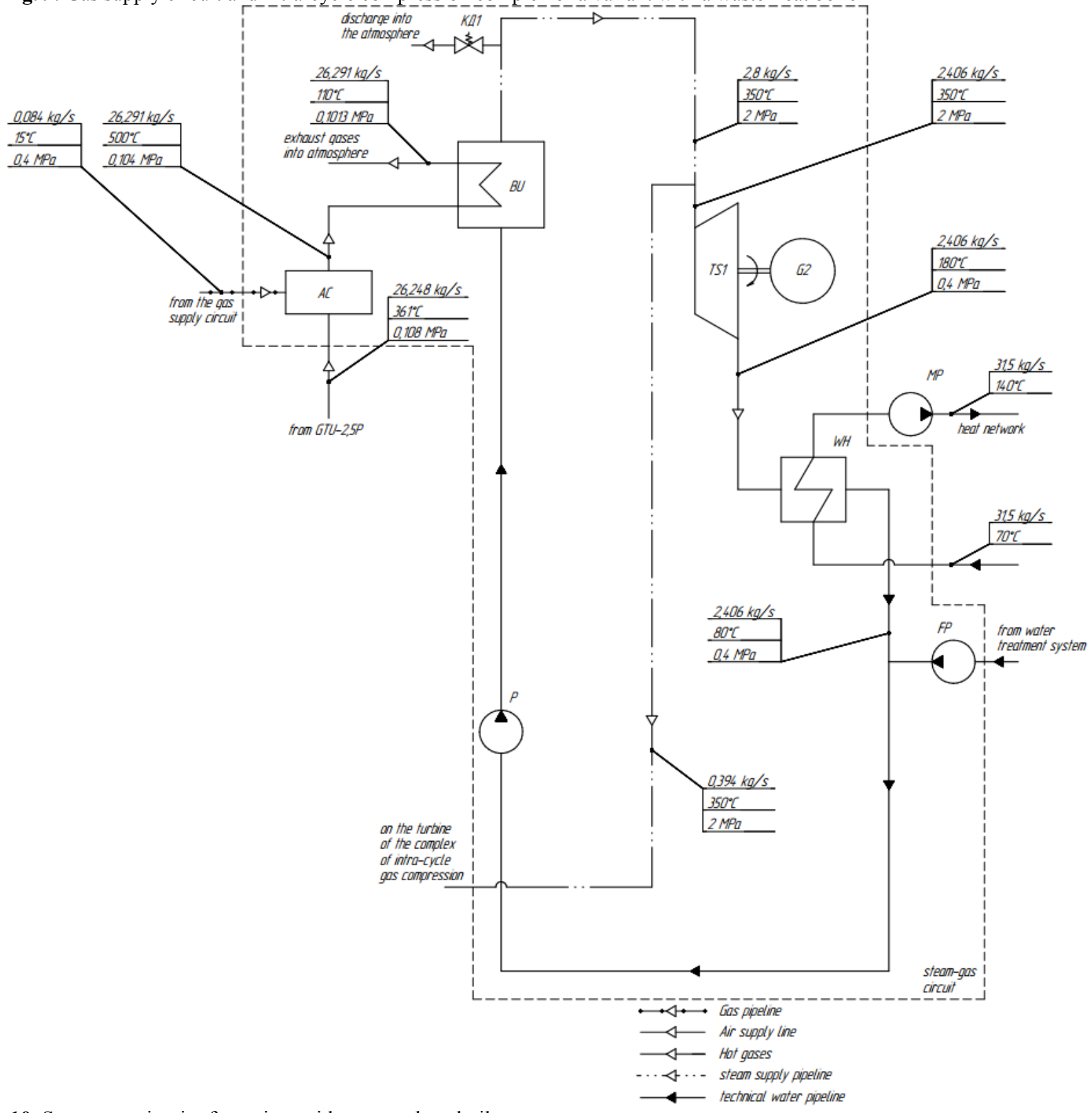

Fig. 10. Steam-gas circuit of a variant with a waste-heat boiler

The main difference of this arrangement from the first option is availability of a supply water circuit as a secondary heat transfer fluid. In this arrangement, all hot gas operated in GTU is transferred to the AC afterburner (fig. 10). In the AC afterburner, the hot gas is mixed with fresh fuel gas and is burned for the second time. It is required in order to increase specifications of the gas mixture before its transfer to the BU waste heat boiler. In the BU waste heat boiler, the gas mixture gives heat to supply water turning it into steam for effective work of steam while passing through the TS1 steam turbine. Before the TS1 steam turbine, steam extraction is created and used for rotation of the TS2 steam turbine contained in the fuel gas intracyclic compression unit. On the shaft of the TS2 steam turbine, there is the G2 power generator which generates electric power. After the TS1 steam turbine, steam is transferred to the WH heating water heater where it is condensed giving heat energy to the heating water which is then used for heating of heat consumers. Then the amount of water lost during the cycle is added to the heating water and the cycle is repeated after the FP supply pump.

The advantage of such arrangement is high power generation (3.4 MW compared to $2.5 \mathrm{MW}$ of the first option) with less fuel flow rate $(0.338 \mathrm{~kg} / \mathrm{s}$ compared to $0.363 \mathrm{~kg} / \mathrm{s}$ of the first option). Heat energy production of both options is equal to $9.318 \mathrm{MW}$. Analysis of the arrangements and above-mentioned data shows that the second option is more efficient in terms of power generation with higher fuel cost effectiveness, but it requires higher investments [11].

Such generating units may be consolidated into clusters containing up to 20 units each. When several generating units are used in a cluster, the system becomes flexible providing the highest cost effectiveness in all energy consumption modes by using 
different quantities of units operating in the most efficient mode.

\section{Conclusions}

To sum up, the following provisions may be specified:

- with all advantages of large-scale power plants, obvious growth of interest in distributed energy is seen;

- a significant share of district and block heating stations has become obsolete and requires reconstruction;

- one of the prospective ways of reconstruction of a district or block heating station is modernization or replacement of the station with a GTU-based energy generating unit due to its efficiency and flexibility;

- for establishment of a GTU-based energy generating unit instead of a district or block heating station, a number of issues requires resolving, the most serious of which is insufficient gas pressure in gas lines of residential districts;

- the alternative to application of a booster compressor station is an intracyclic gas compression attachment;

- based on conditions of operation of gas network, an intracyclic gas compression unit may be developed for each typical GTU, as it was shown using the example of GTU-2.5P;

- the following basic recommendations for design of elements of an intracyclic gas compression unit were formulated:

a) define flow rate and gas compressor pressure ratio

b) define approximate dimensions of an impeller and estimate achievable efficiency factor of a gas compressor

c) on the basis of the first two clauses, define the power to be supplied to a gas compressor for its operation

d) define power of a steam turbine which shall be higher than the power of the gas compressor by 1.5 times

e) select or design a motor generator for adjustment of the turbine-compressor system based on diameter of the gas compressor and steam turbine and provide electric power comparable with them;

- depending on a number of factors including but not limited to expected profit, acceptable amount of investments and reconstruction period, a decision may be made on using one of the two arrangements with an intracyclic gas compression attachment proposed in this article;

- the first arrangement provides application of a hot water boiler of a heating station in more economy mode due to recovery of a part of heat received from a gasturbine engine. Such unit will generate $2.5 \mathrm{MW}$ of electric energy and $9.318 \mathrm{MW}$ of heat energy with fuel flow rate of $0.363 \mathrm{~kg} / \mathrm{s}$;

- the second arrangement requires total reequipment of a heating unit and its conversion into a GTU energy generating unit with a waste heat boiler. But this arrangement will provide higher electric power generation than the first option (3.4 MW), the same amount of heat energy (9.318 MW) with less fuel consumption $(0.338 \mathrm{~kg} / \mathrm{s})$;

- depending in the required electric and heat power, such units may be consolidated in clusters providing full coverage of a consumer load graphs.

As a result of the new approach to resolution of problems of complex power supply of consumers, it is possible to reach significant increase of efficiency of the Russian energy in general by reducing energy losses during its transportation as well as increase of energy network reliability by its higher segmentation degree and achieving management flexibility and less sensitivity to system failures.

\section{References}

1. Power system and centralized heat supply of Russia in 2015-2016. Information and analytical report of the REA Russian Ministry of Energy, 137 p (2018).

2. M.A. Lapyra, The current state of the heat supply system in Moscow and Russia, Energosnabzheniie, no. 4, pp. 18-28 (2003).

3. V. M. Batenin, Iu. A. Zeigarnik, A. S. Kosoy [et al.], Thermodynamic evaluation of the possibility to increase cogeneration turbine efficiency by using a heat pump operating with water vapor, Thermal Engineering, vol.63 no 1, pp. 1-6 (2016).

4. A. S. Kosoy, O.S. Popel, V.N. Beschastnykh [et al.], Low-power gas turbine plants in the power engineering: steps to increase efficiency and widespread introduction, Teploenergetika, no. 10, pp. 25-32 (2017). 5. R.Sh. Zagretdinov, Booster stations, import substitution and supply experience, Gazovaiia promyshlennost, no. 6 (723), pp. 20-24 (2015).

6. D.A. Kalashnikov, A.S. Pugachuk, E. O. Chudotvorova, Determination of power loss in compressor stage of turbogenerator in dynamic experiments, AIP Conference Proceedings, no. 2007 030027, pp.1-7 (2018).

7. V. M. Batenin, Yu. A. Zeigarnik, A. S. Kosoy [et al.], Experimental study of axial compressor working on water steam, Thermal Engineering, vol.62 no. 12, pp. 906-910 (2015).

8. E.Ia. Sokolov, Heat supply and network: textbook for universities. Moscow power engineering institute, $472 \mathrm{p}$ (2001)

9. Gas distribution systems, Rules SP 62.13330.2011 SNiP 42-01-2002, 91 p (2011).

10. I.A. Barskii, Iu.A. Antipov, D.V. Terekhov [et al.], Comparison of combined-cycle plants with a heatutilizer boiler and steam injection into a gas turbine, Tiazheloie mashinostroeniie, no. 7, pp. 15-16 (2009).

11. A.N. Kislitsin, V.A. Begalov Current issues of power supply and increasing the efficiency of energy use in the development of heat supply schemes, Novosti teplosnabzheniia, 2013, no. 5(153), pp. 19-26 (2013). 